5. G.L. Fur and A. Shaniha, UWB filter-antenna using spiral resonator, Loughborough Antennas and Propagation Conference, 2010, pp. 361-364.

6. L. Zhu, H. Bu, and K. Wu, Broadband and compact multipole microstrip band pass filter using ground plane aperture technique, Proc Inst Electr Eng 147 (2002), 71-77.

7. J. Liang, C.C. Chiau, X. Chen, and C.G. Parini, Study of printed circular disc monopole antenna for ultrawideband applications, IEEE Trans Antennas Propag 53 (2005), 3500-3504.

8. S. Kumar, R.D. Gupta, and M.S. Parihar, Multiple band notched filter using C-shaped \& E-shaped resonator for UWB application, IEEE Microwave Wireless Compon Lett 26 (2016), 340-342.

(C) 2017 Wiley Periodicals, Inc.

\section{COMPACT UWB MIMO ANTENNA WITH BAND-NOTCHED CHARACTERISTIC}

\author{
Narges Malekpour, ${ }^{1}$ M. Amin Honarvar, ${ }^{1}$ \\ Abdolmehdi Dadgarpur, ${ }^{2}$ Bal S. Virdee, ${ }^{3}$ and Tayeb A. Denidni ${ }^{2}$ \\ ${ }^{1}$ Department of Electrical Engineering, Najafabad Branch, Islamic \\ Azad University, Najafabad, Isfahan, Iran; Corresponding author: \\ Amin.Honarvar@pel.iaun.ac.ir \\ ${ }^{2}$ The Institute National de la Recherché Scientifique, Energie, \\ Materiaux et Telecommunications (INRS-EMT), Montreal, Canada \\ ${ }^{3}$ Faculty of Life Sciences and Computing, Center for \\ Communications Technology, London Metropolitan University, \\ London, United Kingdom
}

Received 2 March 2016

ABSTRACT: A compact UWB-MIMO antenna with WLAN band notched characteristic is presented. UWB coverage is achieved with two closely spaced planar-monopole elements on the top side of the dielectric substrate with a truncated ground-plane etched on the bottom side. Isolation between the antennas is achieved by creating a current path to decouple energy between the radiation elements using a T-shaped ground stub. Notched frequency band between 5.15 and $5.85 \mathrm{GHz}$ is achieved with a parasitic rectangular strip on the bottom side, which is connected to the radiating patch through a via hole. This approach yields a highly compact antenna design having dimensions of $22 \times 29 \times 0.8 \mathrm{~mm}^{3}$. Simulated and measured results confirm the antenna has an impedance bandwidth of $7.6 \mathrm{GHz}$ from 3.0 to $10.6 \mathrm{GHz}$ making it suitable for UWB MIMO systems. (C) 2017 Wiley Periodicals, Inc. Microwave Opt Technol Lett 59:1037-1041, 2017; View this article online at wileyonlinelibrary.com. DOI 10.1002/mop.30462

Key words: band notched ultra-wideband (UWB) antenna; MIMO antenna; compact antenna; miniaturized antenna

\section{INTRODUCTION}

The multiple-input-multiple-output (MIMO) technology can improve the performance of radio communication systems by providing high spectral efficiency and thereby increasing the channel capacity without using extra spectrum [1]. Installation of multiple antenna elements in a confined space however results in excessive mutual coupling between the antenna elements. This makes the design of compact MIMO antennas for ultra-wideband (UWB) systems very challenging and complex. Although studies have been conducted on MIMO antennas for various wireless systems, including WiMAX and WLAN standards [2,3], the discussion on UWB MIMO antenna is scant in the literature.

Various techniques have been investigated that combine UWB technology with MIMO techniques in order to reduce the mutual coupling between adjacent radiating elements [4-6]. In addition, coexisting inside the UWB spectrum is narrowband

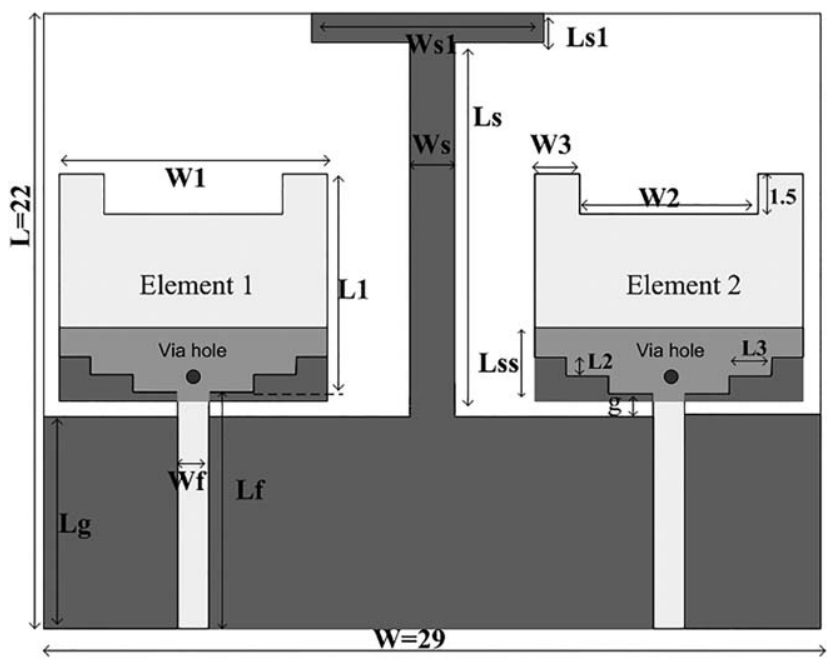

Figure 1 Geometry of the proposed antenna top side, bottom side, $\square$ overlap of metal)

wireless local area network (WLAN) that transmits at substantially higher power level $(20 \mathrm{dBm})$ than the UWB system $(-41 \mathrm{dBm})$; hence WLAN systems can cause EM interference with nearby UWB communication systems. To prevent this interference UWB systems need a notch filter at WLAN band. To minimize system size the notch functionality needs to be implemented in the antenna itself [7-10]. In [7], a stub structure that acts as a band-stop filter is used to reject the WLAN band, and a second radiator is placed perpendicularly to the first element to suppress the coupling between the four elements. In [8], a vertical slot cut on the ground stub is used to reduce mutual coupling, and notched band is created using strip. In [9], a dual reject bands have been realized for UWB MIMO antenna using parasitic strips, and slot in the radiator. The UWB MIMO antenna in [10] has a decoupling structure printed on the bottom side of the substrate which is connected to the patch through the viahole. Here branches are printed on the ground-plane to create dual band rejection at WiMAX and WLAN over the UWB system operation. Some of the methods reported to obtain notched characteristics in planar antennas cause unwanted coupling between nearby antenna elements, such as in [7]. It is evident from the above work the design of compact UWB MIMO antennas with band-notched characteristics and high isolation between radiators is challenging.

In this Letter, an UWB MIMO antenna with WLAN band rejection is presented. This is realized using two identical monopole antennas etched on the top side of the substrate. Mutual coupling between the antennas is suppressed with a $T$-shaped ground-stub which is inserted between the radiating elements. Band notched functionality is achieved with parasitic metal strips etched on the bottom side and connected to the radiating patch through the via-hole. The proposed antenna is compact in size $\left(22 \times 29 \mathrm{~mm}^{2}\right)$, and is smaller than antenna designs

TABLE 1 Dimensions of Proposed Antenna (Unit: $\mathbf{m m}$ )

\begin{tabular}{lccccccc}
\hline$L$ & $L 1$ & $L 2$ & $L 3$ & $L s$ & $L s 1$ & Lss & $L f$ \\
22 & 9 & 0.5 & 1.5 & 12.5 & 1 & 3 & 10 \\
$\mathrm{~W}$ & $\mathrm{~W} 1$ & $\mathrm{~W} 2$ & $\mathrm{~W} 3$ & Ws & Ws1 & $\mathrm{g}$ & Wf \\
29 & 11 & 8 & 1.5 & 1 & 7 & 1.5 & 1.4 \\
\hline
\end{tabular}



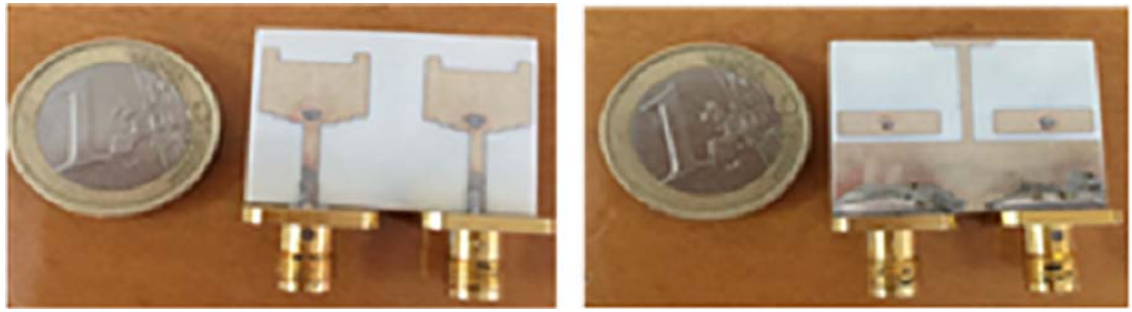

Figure 2 Photographs of the fabricated antenna [Color figure can be viewed at wileyonlinelibrary.com]

reported in [8-10] by 20,21 , and $46 \%$, respectively. The design process is described in details in the following section.

\section{ANTENNA DESIGN}

The geometry of the proposed UWB MIMO antenna, shown of Figure 1, consists of two identical planar monopole elements in close proximity to each other and constructed on the top side of the dielectric substrate. The radiators are U-shaped configurations that are excited by a $50-\Omega$ microstrip feedline of dimensions $W_{\mathrm{f}} \times L_{\mathrm{f}}$. The feedline is attached at the stair case base of the radiators. The antenna was constructed on Rogers substrate, RO4003, with a loss tangent of 0.0027 , a dielectric constant $\varepsilon_{\mathrm{r}}$ of 3.55 and a thickness of $0.8 \mathrm{~mm}$. The frequency corresponding
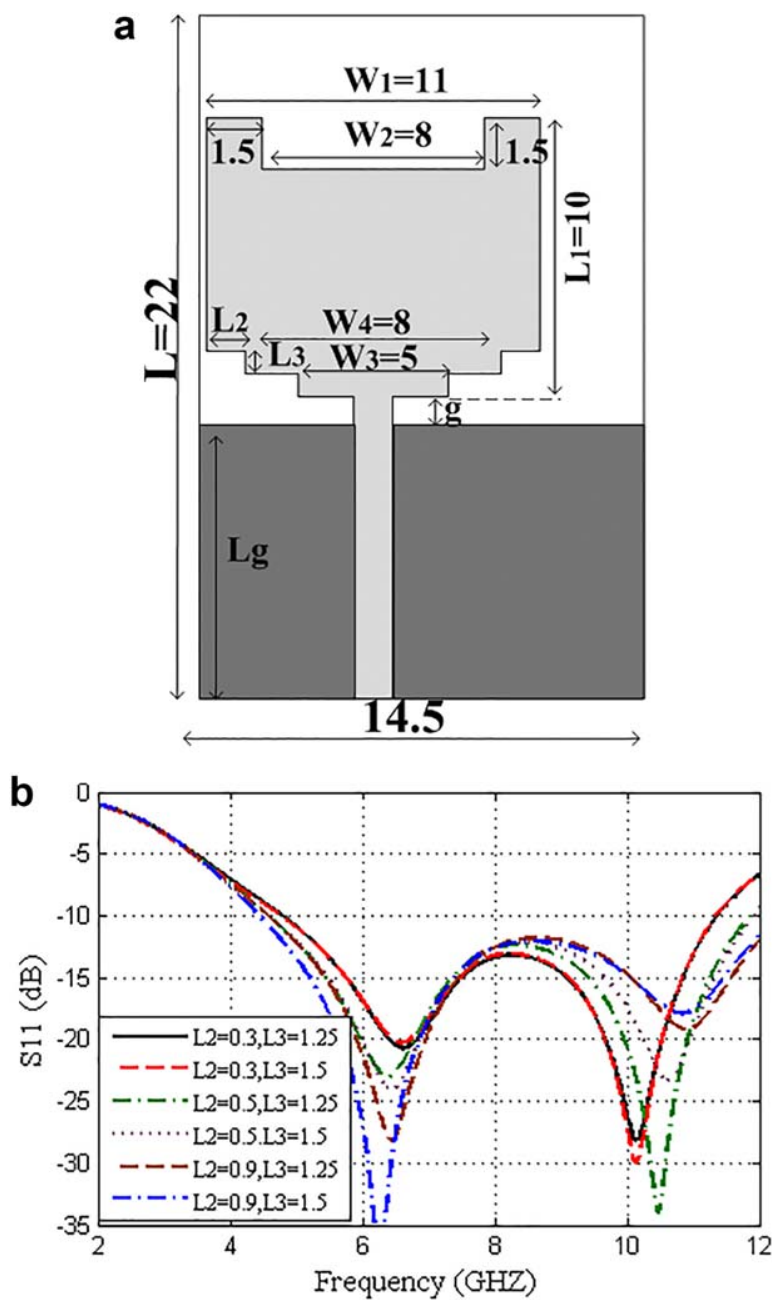

Figure 3 (a) Configuration, and (b) $\left|S_{11}\right|$ of UWB antenna. [Color figure can be viewed at wileyonlinelibrary.com]
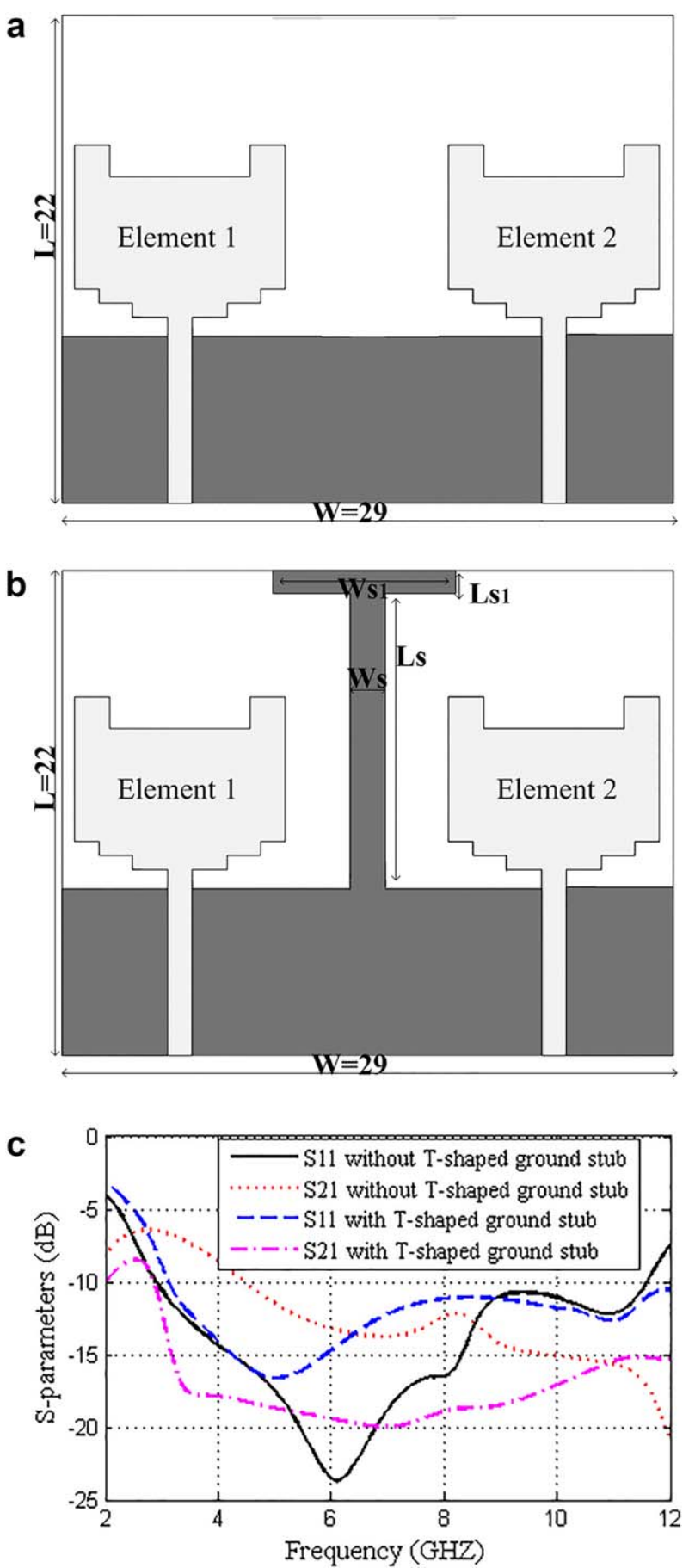

Figure 4 (a) Configuration of antenna 1, (b) configuration of antenna 2 , and (c) $\left|S_{11}\right|$ of antennas 1 and 2. [Color figure can be viewed at wileyonlinelibrary.com] 

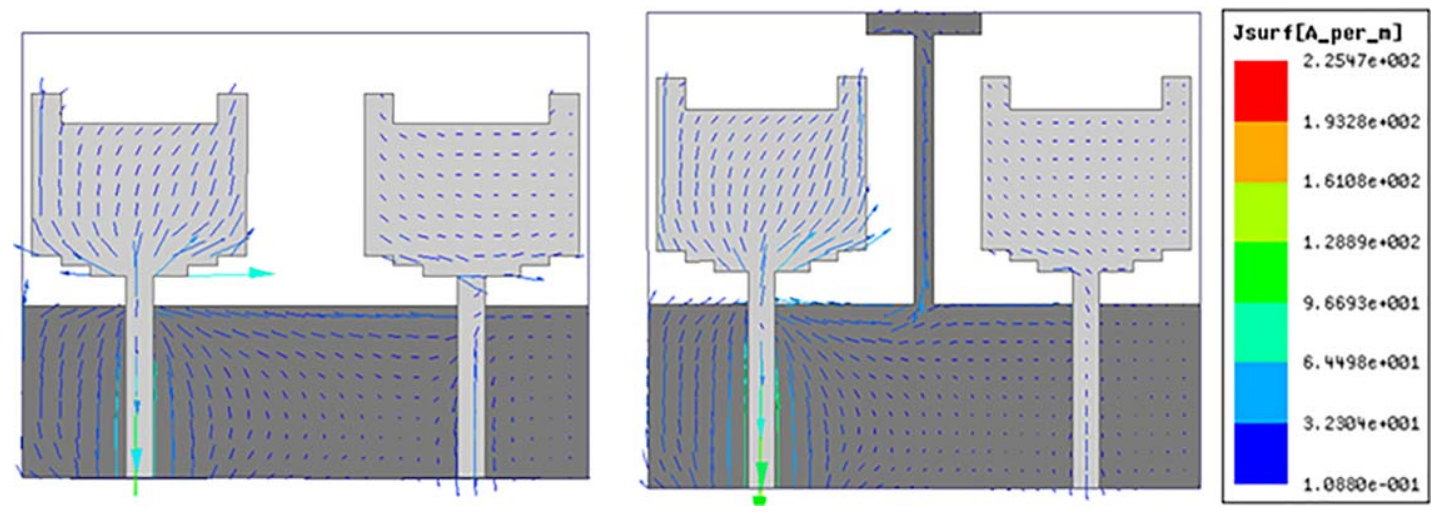

Figure 5 Current distribution of the UWB MIMO antenna with and without $T$-shaped ground stub. [Color figure can be viewed at wileyonlinelibrary. com]

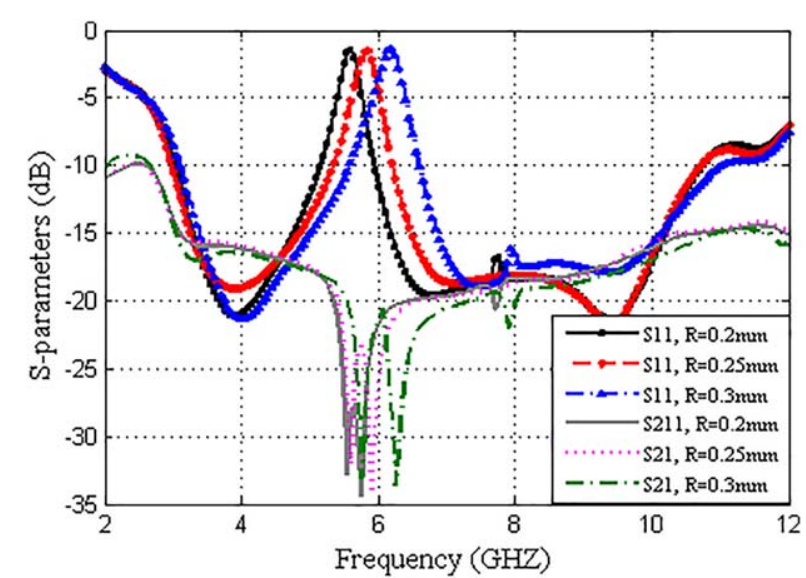

Figure 6 S-parameter with different values of radius. [Color figure can be viewed at wileyonlinelibrary.com]

to the lower resonance of a planar monopole antenna can be approximated by [9]

$$
F_{\mathrm{r} l}=\frac{144}{L_{1}+L_{2}+g+\frac{A_{1}}{2 \pi A L_{1} \sqrt{1+\varepsilon_{r e}}}+\frac{A_{2}}{2 \pi L_{2} \sqrt{1+\varepsilon_{r e}}}}(\mathrm{GHz})
$$

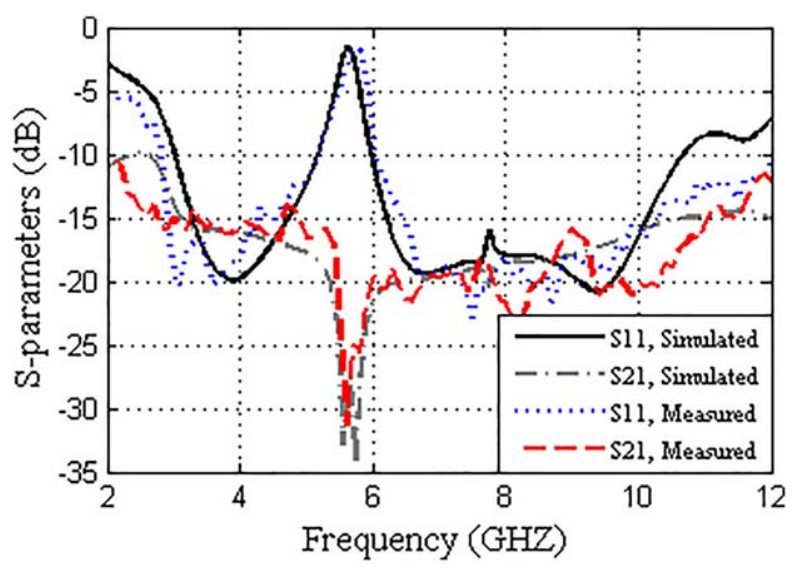

Figure 7 The measured and simulated S-parameters. [Color figure can be viewed at wileyonlinelibrary.com]
The truncated ground-plane is constructed on the bottom side of the substrate where a $T$-shaped ground stub protruding vertically between the monopole elements is used to enhance the isolation between the elements. For each radiating element, there is an overlapping rectangular metal strip that is constructed on the bottom side of the substrate. The metal strip is connected to the radiator with a via-hole, as shown in Figure 1, whose function is generate a notched band between 5.15 and $5.85 \mathrm{GHz}$, and thus prevent interference from WLAN systems. Dimensions of the ground-plane are $W \times L_{\mathrm{g}}$, and the two metal strips under each radiator have are $3 \times 11 \mathrm{~mm}^{2}$. Optimized dimensions for the MIMO antenna, listed in Table 1, were used to fabricate the prototype antenna shown in Figure 2.

\subsection{UWB Antenna Design}

The $U$-shaped planar monopole antenna was designed centered at $6.8 \mathrm{GHz}$ using Eq. (1). The dimensions of the antenna are given in Figure 3(a). The affect of the stair case base on the antenna's $S_{11}$ performance is shown in Figure 3(b). The simulation analyzes shows the optimum impedance match is achieved when $L_{2}=0.9 \mathrm{~mm}$ and $L_{3}=1.5 \mathrm{~mm}$. Although the bandwidth of a single antenna cannot cover the entire UWB spectrum, however can be overcome by using two closely spaced antennas to cover a much wider impedance bandwidth of the UWB spectrum, as shown in Figure 4(a).

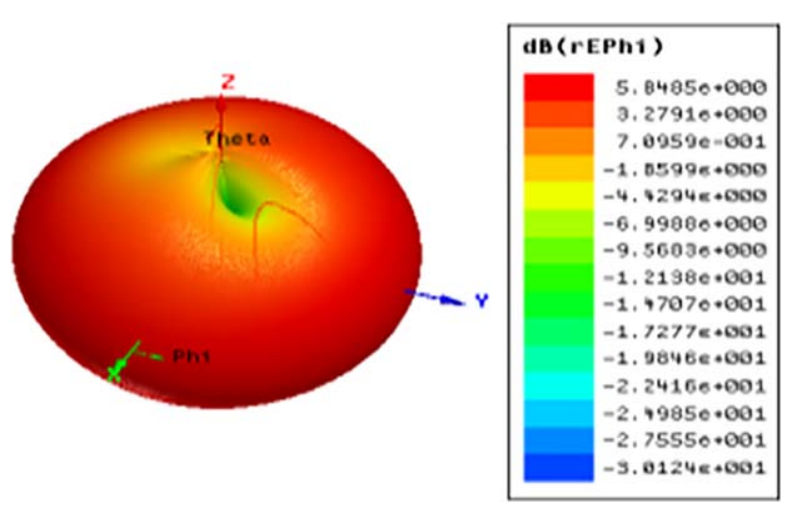

Figure 8 3D radiation patterns at $5.6 \mathrm{GHz}$ with port 1 excited and port 2 terminated with $50 \Omega$ load. [Color figure can be viewed at wileyonlinelibrary.com] 


\begin{tabular}{lcccc}
\hline & $\begin{array}{c}\text { Bandwidth } \\
(\mathrm{GHz})\end{array}$ & $\begin{array}{c}\text { Size } \\
\left(\mathrm{mm}^{2}\right)\end{array}$ & $\begin{array}{c}\text { Relative size of } \\
\text { proposed work }\end{array}$ & $\begin{array}{c}\text { Band } \\
\text { notched } \\
\text { freq. }(\mathrm{GHz})\end{array}$ \\
\hline Ref [7] & $3.1-10.6$ & $50 \times 40$ & $-68 \%$ & $-19.4 \%$ \\
Ref [8] & $3.1-10.6$ & $22 \times 36$ & $-21.2 \%$ & $-15-5.85$ \\
Ref [9] & $3.1-10.6$ & $27 \times 30$ & $-47 \%$ & 515 \\
Ref [10] & $3.1-10.6$ & $30 \times 40$ & - & $5.15-5.85$ \\
This work & $3.1-10.6$ & $22 \times 29$ & $5.15-5.85$ & $>15$ \\
\hline
\end{tabular}

a1

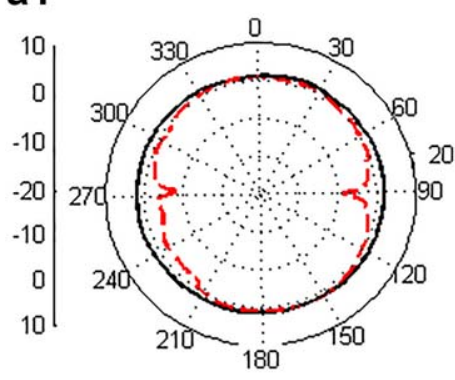

b1

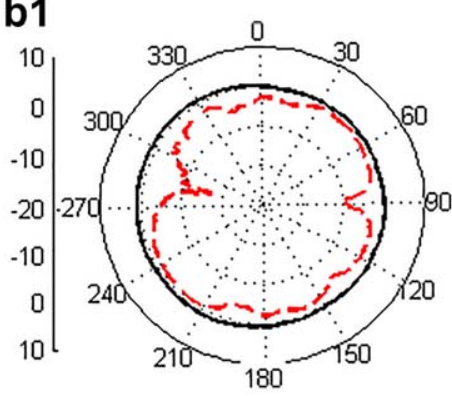

a2

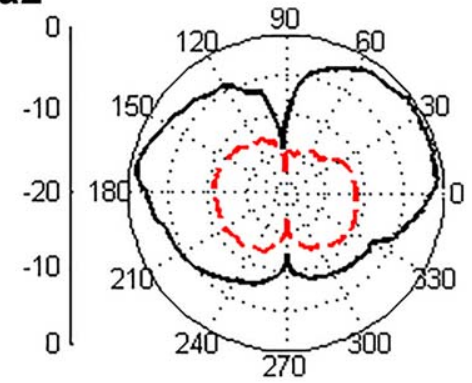

b2

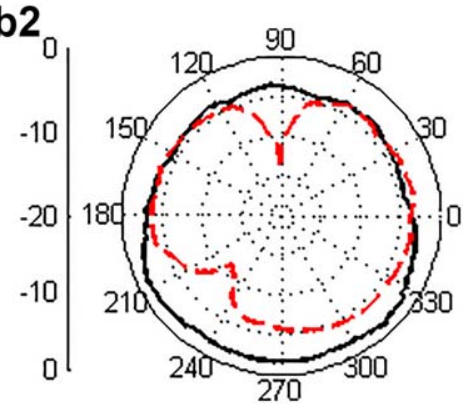

a3

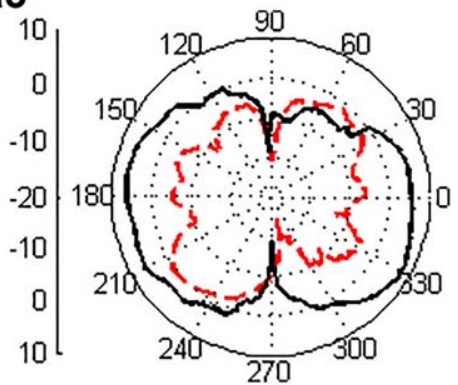

b3.

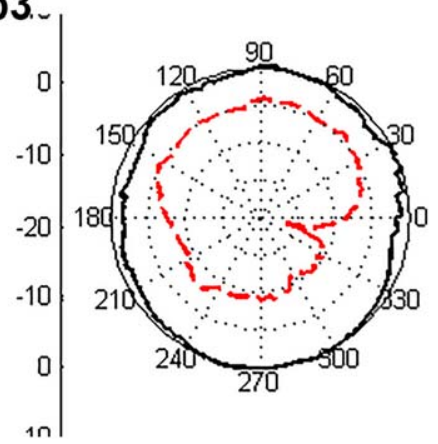

Figure 9 Measured 2D radiation patterns of the proposed MIMO antenna: (a) $x-z$ plane and (b) $y-z$ plane. [Color figure can be viewed at wileyonlinelibrary.com]

\subsection{Effects of T-Shaped Ground Stub}

Edge-to-edge spacing between the antenna elements in Figure 4(a) is $6 \mathrm{~mm}$. To achieve good isolation, a $T$-shaped ground stub is applied as shown in Figure 4(b). The affect of the $T$ shaped ground stub on the antenna response is shown in Figure 4(c). The isolation $\left(S_{21}\right)$ without the $T$-shaped ground stub between 3.1 and $4.5 \mathrm{GHz}$ of less than $-10 \mathrm{~dB}$ is unacceptable. However, with the $T$-shaped ground stub the isolation is greater than $-10 \mathrm{~dB}$ across the entire UWB frequency range.

Current distribution over the antenna with and without the $T$-shaped ground stub at $4 \mathrm{GHz}$ is shown in Figure 5. When Port 1 is exited and Port 2 is terminated with a $50 \Omega$ load strong current is induced on Port 2 with no $T$-shaped ground stub. However, when the $T$-shaped ground stub is inserted between the antennas it creates another current path that decouples energy from the antennas to enhance isolation between the two ports.

\subsection{Band Rejection Function for WLAN Band}

Transmission power of UWB systems $(3.1-10.6 \mathrm{GHz})$ is limited to $-41 \mathrm{dBm}$. This makes UWB systems prone to interference from much stronger narrowband wireless communication systems, such as WLAN operating at $5.8 \mathrm{GHz}$. To suppress this interference, rejection band functionality is incorporated in the antenna by printing two parasitic metal strips of dimensions

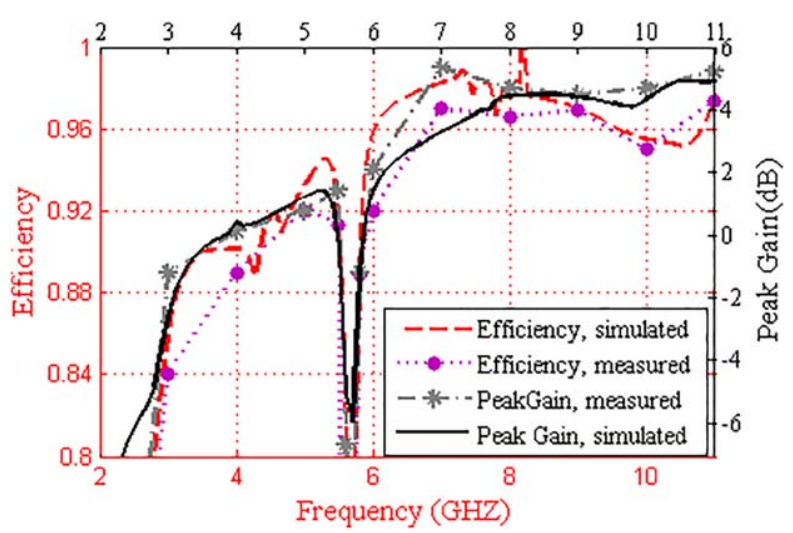

Figure 10 Simulated and measured peak gain and radiation efficiency. [Color figure can be viewed at wileyonlinelibrary.com] 


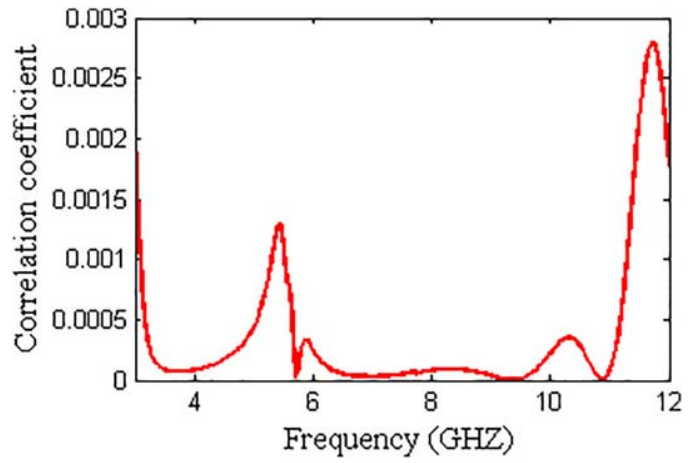

Figure 11 Correlation coefficient for the MIMO antenna. [Color figure can be viewed at wileyonlinelibrary.com]

$3 \times 11 \mathrm{~mm}^{2}$ on the bottom side of the antenna substrate. The parasitic strips are connected to the radiation patch through a via-hole. This technique enables the notched band frequency to be tuned by varying the radius of the via-hole, as shown in Figure 6. Modifying the radius from 0.2 to $0.3 \mathrm{~mm}$, the notched frequency drops from 6.2 to $5.4 \mathrm{GHz}$, while $S_{21}$ remains below $-15 \mathrm{~dB}$ across the UWB spectrum.

\section{RESULTS AND DISCUSSION}

\subsection{S-Parameters}

The simulated and measured reflection coefficient characteristics of the proposed antenna are shown in Figure 7. The fabricated antenna was measured using a vector network analyzer (Agilent $8719 \mathrm{~A})$. The measured return loss is better than $-10 \mathrm{~dB}$ from 3 to $10.7 \mathrm{GHz}$ except at the notched band between 5.15 and $5.9 \mathrm{GHz}$. The isolation is measured to be better than $-15 \mathrm{~dB}$. Suppression in the notch band is high indicated by $S_{11}$ of $-1.49 \mathrm{~dB}$. Figure 7 shows there is generally good correlation between the simulated and measured results and the discrepancy is mainly attributed to the manufacturing tolerance and lossy SMA connectors. Comparison of the proposed antenna in terms of bandwidth, size and isolation with recently reported UWB MIMO antennas is given in Table 2. The table shows the proposed antenna satisfies the UWB requirement with high isolation and is the smallest in size.

\subsection{Radiation Patterns}

The 3D radiation pattern of the proposed antenna at the notch frequency of $5.6 \mathrm{GHz}$ is shown in Figure 8. The simulated and measured $2 \mathrm{D}$ radiation patterns of the antenna at the frequencies of 3,5.6, and $10 \mathrm{GHz}$ in the $x-z(\mathrm{H})$ and $y-z$ (E) planes are shown in Figure 9. During the measurements, only Port 1 excited, while Port 2 is terminated with a $50-\Omega$ load.

The simulated and measured realized peak gain of the antenna with Port 1 excited and Port 2 terminated with $50-\Omega$ load is shown in Figure 10. There is generally good agreement between the simulated and measured results. The measured peak gain varies between -2 and $6 \mathrm{dBi}$ across $3-12 \mathrm{GHz}$, and the antenna radiates with an efficiency of above 90\% across the UWB except for the notched band.

\subsection{Diversity Performance}

Two-port envelope correlation coefficient (ECC) is an important parameter to consider for antenna applications in MIMO systems. ECC is a measure of how much isolation/correlation exists between adjacent communication channels. ECC can be calculated using the method in [11] using:

$$
\rho_{e}=\frac{\left|s_{12} s_{11}^{*}+s_{22} s_{21}^{*}\right|^{2}}{\left[1-\left(\left|s_{11}\right|^{2}+\left|s_{21}\right|^{2}\right)\right]\left[1-\left(\left|s_{22}\right|^{2}+\left|S_{12}\right|^{2}\right)\right]}
$$

The calculated ECC in Figure 11 shows that the proposed antenna has an ECC less than 0.003 over the complete UWB frequency band. This verifies the antenna is suitable for MIMO systems.

\section{CONCLUSION}

Two adjacent planar-monopole antenna elements are used to implement a compact UWB antenna with interference rejection from narrowband WLAN systems. Mutual coupling between the two monopole antennas is suppressed with a $T$-shaped ground stub implemented between the antennas in the bottom side of the antenna substrate. Parasitic metal strips constructed on the bottom side, which are connected to the radiators through the via-hole, create a notched frequency centered at WLAN band. The proposed design is highly compact with dimension of $22 \times 29 \mathrm{~mm}^{2}$. The mutual coupling between the radiators is less than $-15 \mathrm{~dB}$, and the envelope correlation coefficient is less than 0.003 . These characteristics make the antenna a good candidate for handheld and portable UWB systems.

\section{REFERENCES}

1. L. Zheng and N.C. Tse, Diversity and multiplexing: A fundamental tradeoff in multiple-antenna channels, IEEE Trans Inform Theory 49 (2003), 1073-1096.

2. F. Yang and Z.M. Wang, Reducing mutual coupling of closely spaced microstrip MIMO antennas for WLAN application, IEEE Antennas Wireless Propag Lett 10 (2011), 310-313.

3. S.W. Su, C.T. Lee, and F.S. Chang, Printed MIMO-antenna system using neutralization-line technique for wireless USB dongle applications, IEEE Trans Antennas Propag 60 (2012), 446-463.

4. L. Liu, S.W. Cheung, and T.I. Yuk, Compact MIMO antenna for portable devices in UWB applications, IEEE Trans Antenna Propag 61 (2013), 4257-4264.

5. J. Ren, W. Hu, Y. Yin, and R. Fan, Compact printed MIMO antenna for UWB applications, IEEE Antennas Wireless Propag Lett 13 (2014), 1517-1520.

6. C. Luo, J. Hong, and L. Zhong, Isolation enhancement of very compact UWM-MIMO slot antenna with two defected ground structures, IEEE Antennas Wireless Propag Lett (2015), 1766-1769.

7. M.S. Khan, A.D. Capobianco, S. Asif, A. Iftikhar, B. Ijaz, and B.D. Braaten, Compact $4 \times 4$ UWB-MIMO antenna with WLAN band rejected operation, Electron Lett 51 (2015), 1048-1050.

8. L. Liu, S.W. Cheung, and T.I. Yuk, Compact MIMO antenna for portable UWB applications with band-notched characteristic, IEEE Trans Antenna Propag 63 (2015), 1917-1924.

9. J.F. Li, Q.X. Chu, Z.H. Li, and X. Xia, Compact dual band notched UWB MIMO antenna with high isolation, IEEE Trans Antennas Propag 61 (2013), 4759-4766.

10. T. Tang and K. Lin, An ultrawideband MIMO antenna with dual band-notched function, IEEE Trans Antennas Propag 61 (2014), 4759-4766.

11. S. Blanch, J. Romeu, and I. Corbella, Exact representation of antenna system diversity performance from input parameter description, Electron Lett 39 (2003), 705-707.

(C) 2017 Wiley Periodicals, Inc. 